\title{
DO BRANCO AO NEGRO, DA ELITE AO POPULAR: CULTURA VISUAL, FOTOGRAFIA E FUTEBOL NO INÍCIO DO SÉCULO XX
}

From white to black, from elite to the popular: visual culture, photography and soccer in the early $20^{\text {th }}$ century

Del blanco al negro, de la élite a lo popular: cultura visual, fotografía y fútbol de principios des siglo $\mathrm{XX}$

DIANA MENDES MACHADO DA SILVA ${ }^{\mathrm{I}^{*}}$

DOI: https://doi.org/10.1590/S2178-149420210106

'Centro de Referência do Futebol Brasileiro do Museu do Futebol - São Paulo (SP), Brasil.

*Coordenadora do Centro de Referência do Futebol Brasileiro do Museu do Futebol (dmendesmachadodasilva@yahoo. com.br; diana.mendes@idbr.org.br)

(D) https://orcid.org/0000-0001-9559-163X

Artigo recebido em 01 de setembro de 2020 e aprovado para publicação em 11 de novembro de 2020. 


\title{
RESUMO
}

Que tipo de informação os retratos dos clubes Andarahy, Carioca e Mangueira podem oferecer sobre a cultura visual do Rio de Janeiro no início do século XX e sobre a transição do futebol amador ao profissional? Em contraste com imagens da aristocrática equipe do Fluminense Football Club, os retratos dos jogadores negros desses clubes populares revelam disputas por visibilidade no campo esportivo e no espaço urbano já a partir do fim da década de 1910. Revelam ainda o papel do mercado fotográfico na coprodução de signos capazes de compor uma nova visualidade para a população negra. Nessa medida, as transformações socioculturais desse período foram mais significativas do que se costuma reconhecer ao representarem o protagonismo da população negra nas negociações sobre a visibilidade social na capital do país.

PALAVRAS-CHAVE: Cultura Visual; Fotografia; Futebol; Visibilidade; População Negra.

\begin{abstract}
What kind of information can the portraits of the Andarahy, Carioca, and Mangueira clubs offer about the visual culture of Rio de Janeiro in the early $20^{\text {th }}$ century and the transition from amateur to professional soccer? In contrast to images from the aristocratic team of the Fluminense Soccer Club, the portraits of the black players of these popular clubs reveal disputes for visibility in the sports field and in the urban space since the end of the 1910s. They also reveal the role of the photographic market in the co-production of signs capable of composing a new visuality for the black population. To that extent, the socio-cultural transformations of that period were more significant than is usually recognized by representing the protagonism of the black population in the negotiations around social visibility in the country's capital.
\end{abstract}

KEYWORDS: Visual Culture; Photography; Football; Visibility; Black Population.

\section{RESUMEN}

¿Qué tipo de información pueden ofrecer los retratos de los clubes Andarahy, Carioca y Mangueira sobre la cultura visual de Río de Janeiro a principios del siglo XX y la transición del fútbol amateur al profesional? A diferencia de las imágenes del aristocrático equipo del Fluminense Football Club, los retratos de los jugadores negros de estos populares clubes revelan disputas por la visibilidad en el campo deportivo y en el espacio urbano desde finales de la década de 1910. También revelan el papel del mercado fotográfico en la coproducción de signos capaces de componer una nueva visualidad para la población negra. En esa medida, las transformaciones socioculturales de ese período fueron más significativas de lo que se suele reconocer al representar el protagonismo de la población negra en las negociaciones en torno a la visibilidad social en la capital del país.

PALABRA ClAVES: Cultura Visual; Fotografía; Fútbol; Visibilidad; Población Negra. 


\section{RIO DE JANEIRO: CIDADE TORNADA CENÁRIO}

$\mathrm{O}$ $s$ anos iniciais do futebol no Rio de Janeiro coincidiram com a série de transformações urbanas que modificou profundamente a sociabilidade e a sensibilidade de seus cidadãos. As transformações empreendidas por Pereira Passos entre 1903 e 1906, as mais importantes da época, foram especialmente responsáveis por uma variação nas formas de ver e de dar a ver os acontecimentos da cidade.

Fotografias da cidade renovada que circulavam em cartões postais, panoramas, revistas ilustradas etc. faziam ver as mudanças espaciais e também definiam aqueles que poderiam tomar parte em seu novo centro, ou seja, aqueles que poderiam assumir uma aparência por meio da qual negociar visibilidade e reconhecimento social.

No bojo dessa renovação, certos espaços e práticas esportivas passaram a ser valorizados pelo poder público como representativos do novo espaço urbano que se desejava configurar. Assim, registros fotográficos que focalizavam espaços como o Fluminense Football Club, práticas como o futebol e personagens como o goleiro Marcos Carneiro de Mendonça' foram sistematicamente realizados, ajudando a fixar novas formas para a sociabilidade esportiva na cidade.

Vinculados ao bem-estar, à saúde e à vida ao ar livre, tais registros reiteravam a gramática higienista ao mesmo tempo em que valorizavam o tipo de circulação desejada para as praças de esportes. Foi nesse contexto que as imagens de conteúdo esportivo ou lúdico associadas ao Fluminense ajudaram a validar o ciclo de renovação dos espaços centrais da cidade do Rio de Janeiro, ao mesmo tempo em que valorizavam os personagens a eles associados.

A figura de Marcos Carneiro de Mendonça, por exemplo, foi tão explorada que acabou se tornando sinônimo de sportsman, ou seja, de homem guiado pelos valores associados ao esporte. 0 cronista Mario Filho frequentemente mencionava o sportsman Marcos referindo-se aos seus trajes:

Marcos de Mendonça usava camisa tipo esporte, ampla, de mangas compridas. Os "outros" gostavam das camisas de lã, pesadas, como aquelas camisas usadas pelos boxeurs, pesos pesados, que precisam perder peso. Mais tarde é que apareceram as camisas de mangas curtas, leves. Umas de seda. Outras de linho. E Marcos até hoje não compreende por que alguns goleiros abandonaram as mangas compridas. Ele não usava manga comprida por elegância. E sim por conveniência. Para amortecer a bola. Como uma ajuda para um controle mais perfeito da esfera de couro. (Rodrigues Filho, 1994).

Ora, mais importante do que as imagens associadas ao trabalho eram as imagens sobre o que fazer com o tempo livre. Desse modo, as imagens fotográficas que mais circularam no período - em jornais, revistas ilustradas e suportes de caráter privado, como os álbuns de 
memórias - eram aquelas associadas ao projeto de renovação da paisagem urbana, que contribuíam para que esportes como o futebol e seus praticamentes fossem altamente valorizados.

Oriundas de arquivos da família, as três fotografias (Figuras 1, 2 e 3) destacam o jogador mesmo quando se trata de um retrato de equipe. Seu destacado uniforme de seda branco, as poses do jogador, mais controladas do que as de seus companheiros, e a posição central por ele assumida já são suficientes para denotar sua importância na equipe, bem como sua capacidade de encarnar a figura do sportsman².

A frequência com que imagens como essas apareceram na imprensa torna possível afirmar que, por causa de personagens como Marcos, o futebol dos anos 1910-1920 segue sendo visto como um esporte "branco", "amador" e de "elite". Ainda que se saiba por outras fontes que os segmentos populares praticavam o futebol tanto quanto os segmentos elitiza-

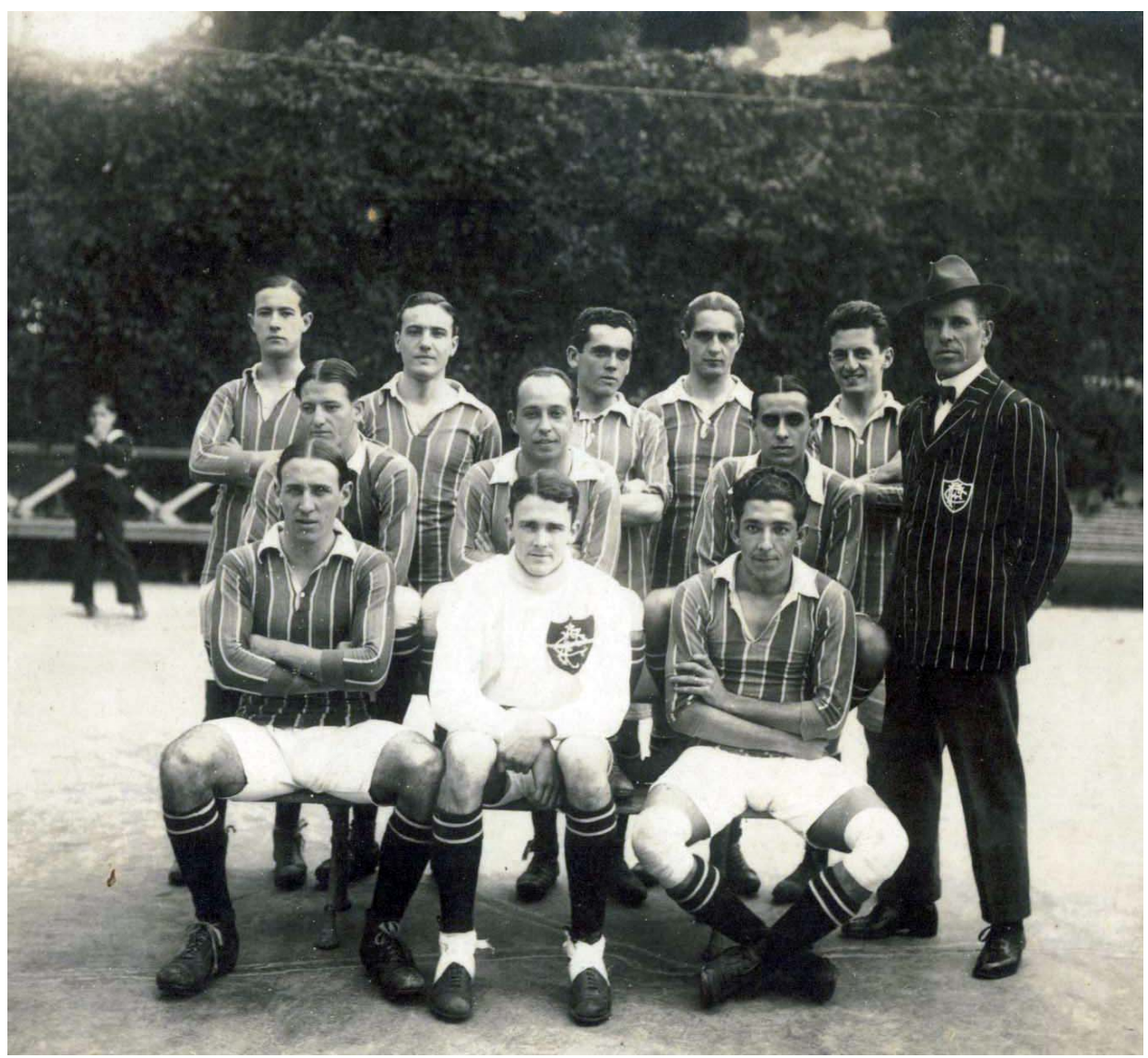

Figura 1 - Marcos Carneiro de Mendonça e equipe do Fluminense, 1914. Acervo da família. 
dos, desde os anos iniciais da chegada do esporte à cidade (cf. Pereira, 2000), raros foram os registros propriamente visuais, fotográficos, dessa experiência. Assim, ao menos nos anos iniciais do esporte na cidade, não foi possível associá-lo a esses grupos.

Contudo, já no fim da década de 1910, imagens como as seguintes (Figuras 4, 5, 6 e 7), que destacam homens de cor negra, passaram a circular nos álbuns do Fluminense Football Club e até mesmo do goleiro Marcos.

\section{NOVOS PERSONAGENS NO CENÁRIO FUTEBOLÍSTICO}

ra, se toda "fotografia nos apresenta duas mensagens: uma concernente ao evento fotografado e outra concernente a um choque de descontinuidade" (Berger, 2017: 89),

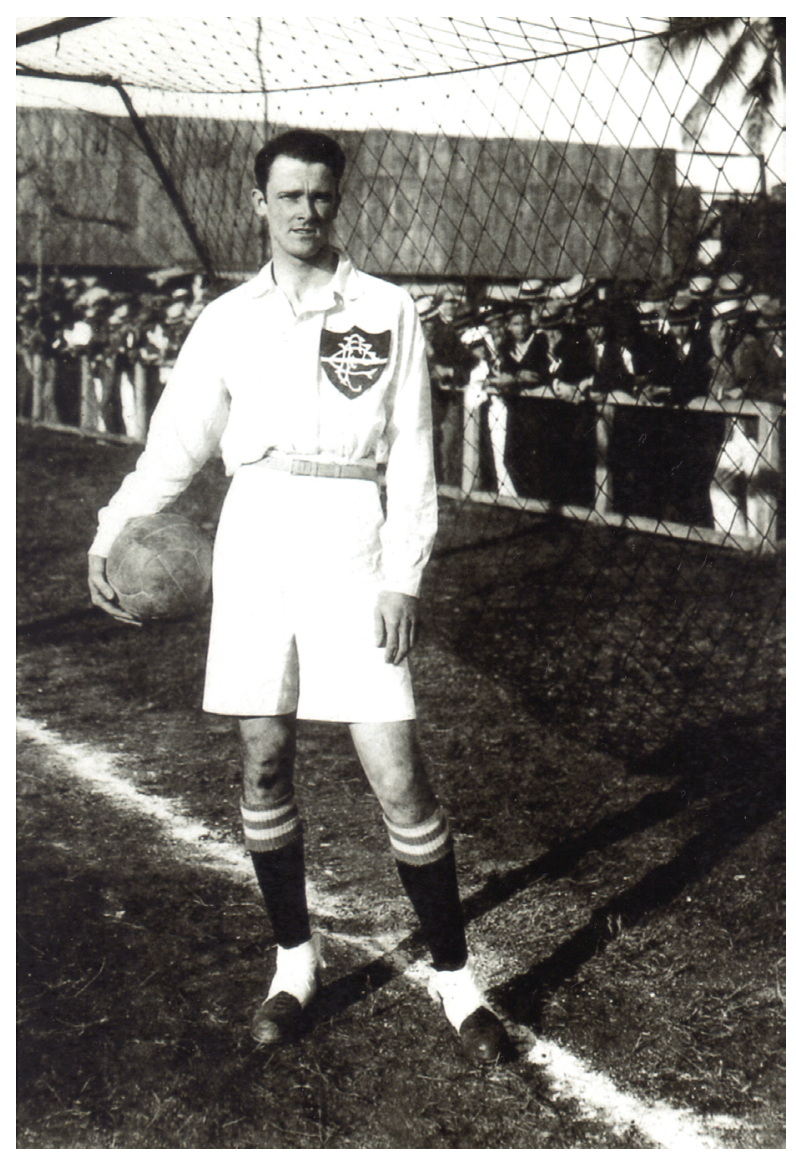

Figura 2 - Marcos Carneiro de Mendonça em uniforme do Fluminense, 1914. Acervo da família. 


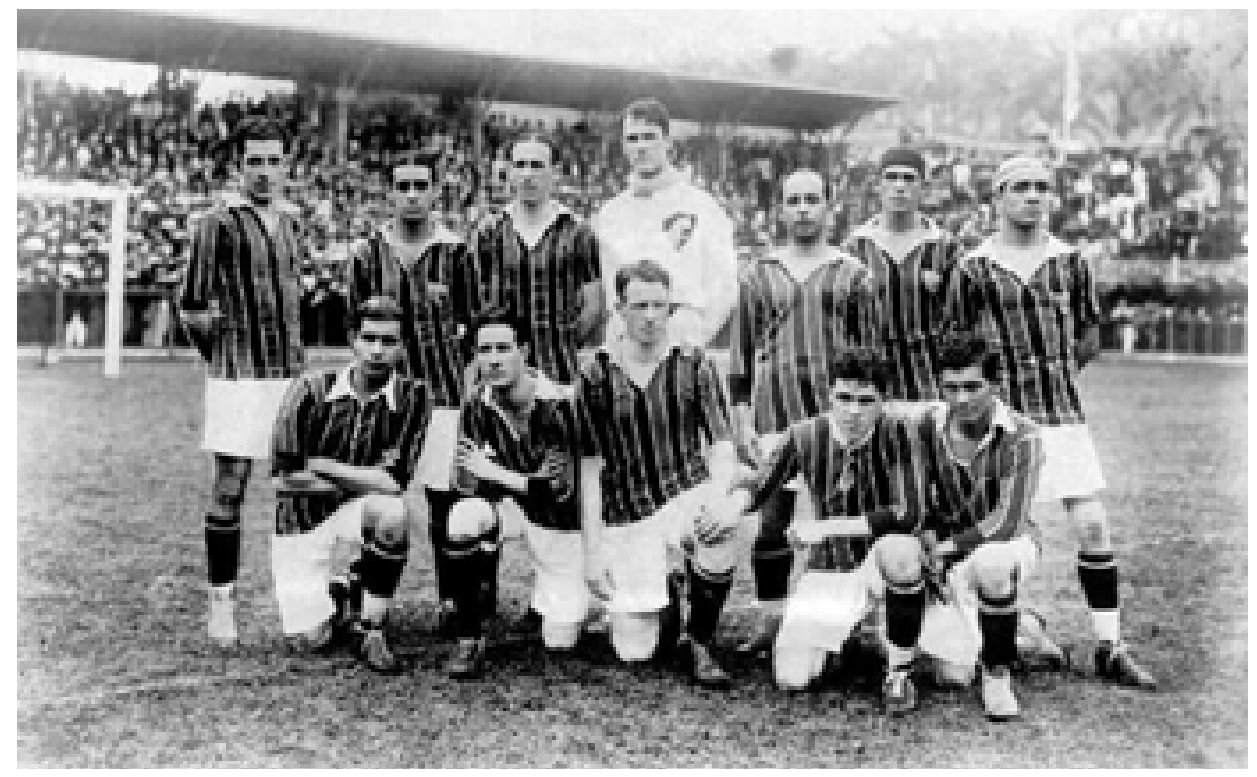

Figura 3 - Fluminense Football Club. Campeonato de 1917.

Fonte: <https://saudacoestricolores.com/idolos-zeze/> Acesso em: 20 nov. 2020.

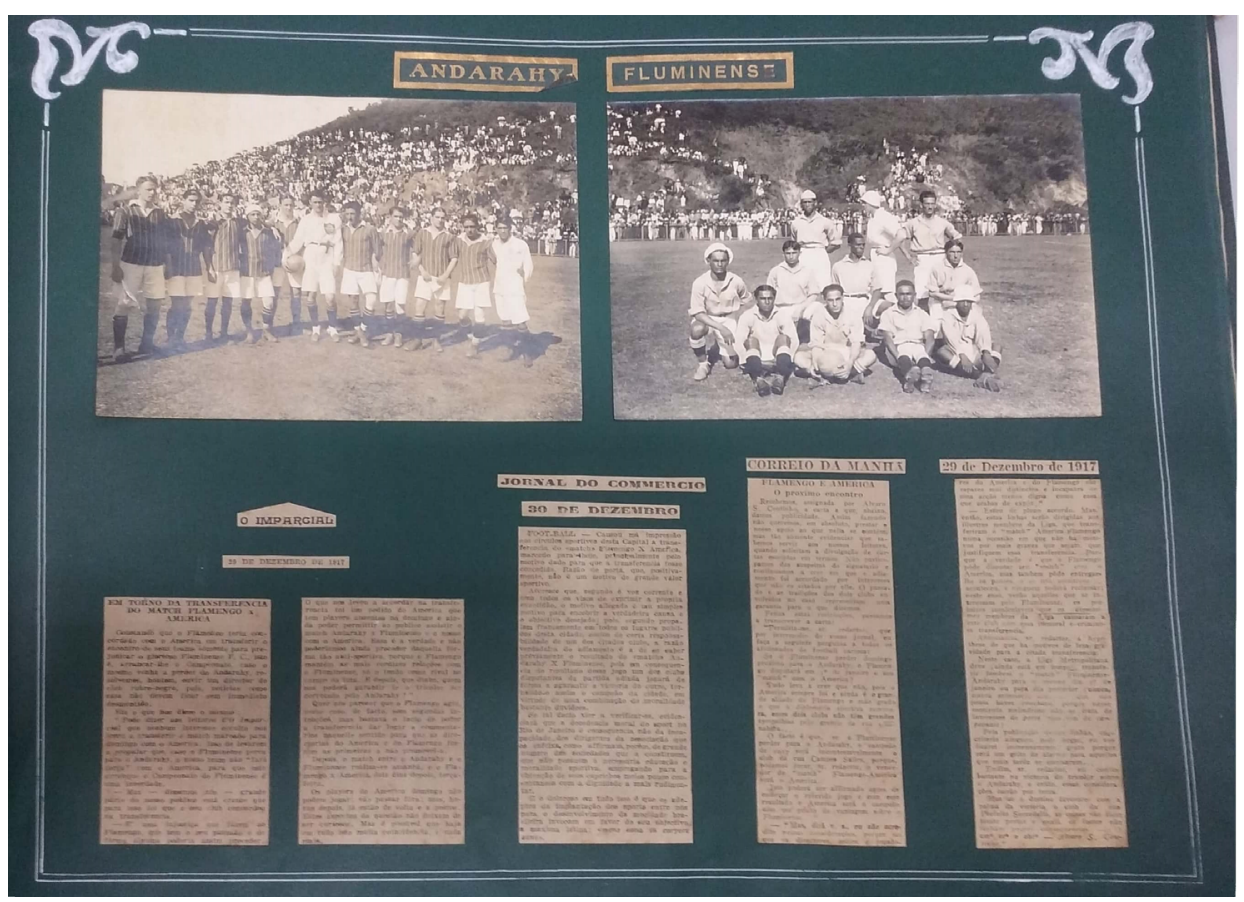

Figura 4 - Andarahy vs. Fluminense. Ampliações fotográficas. Fonte: Álbum do Fluminense, 1917. Fotografia, s/d 


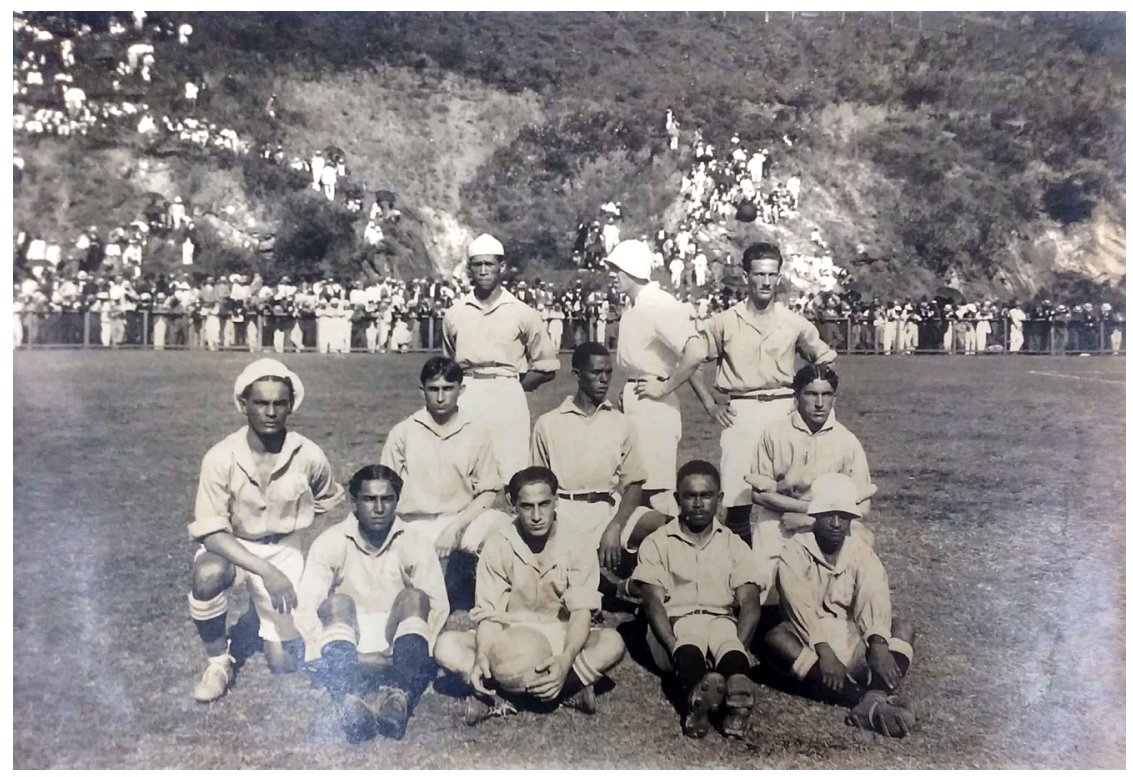

Figura 5 - Detalhe: equipe do Andarahy. Fonte: Álbum do Fluminense, 1917, s/p.

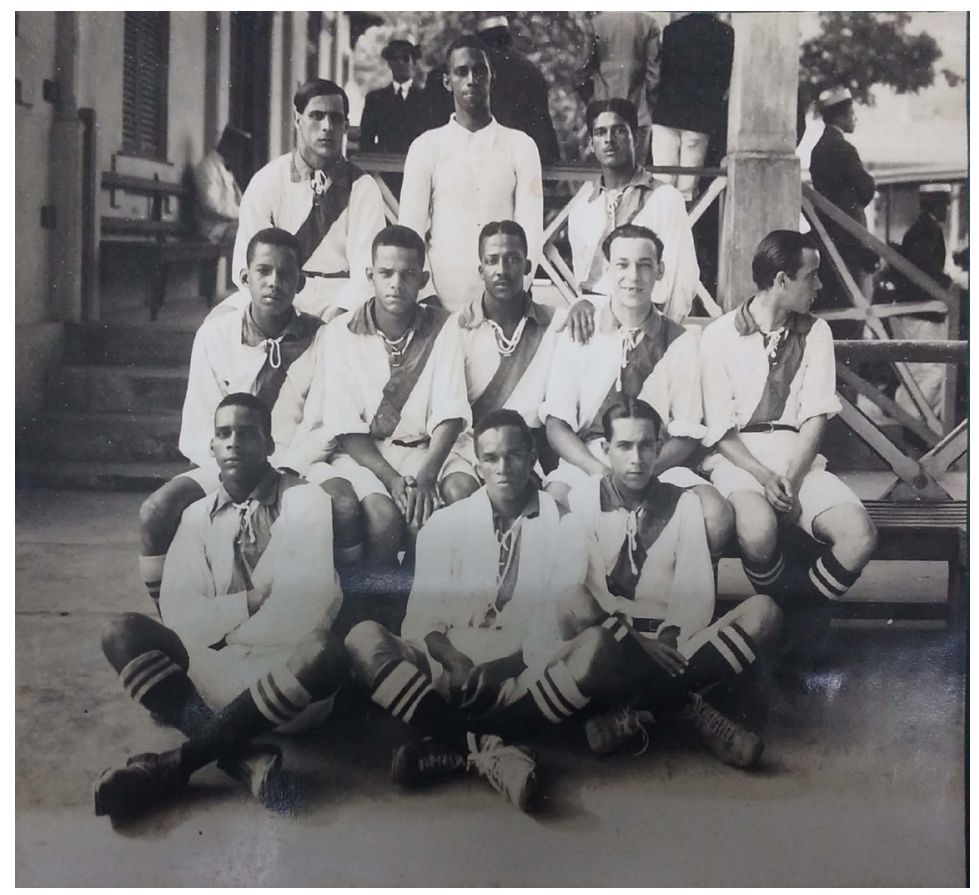

Figura 6 - Equipe do Carioca Futebol Clube. Fonte: Álbum do Fluminense, 1917, s/p. 


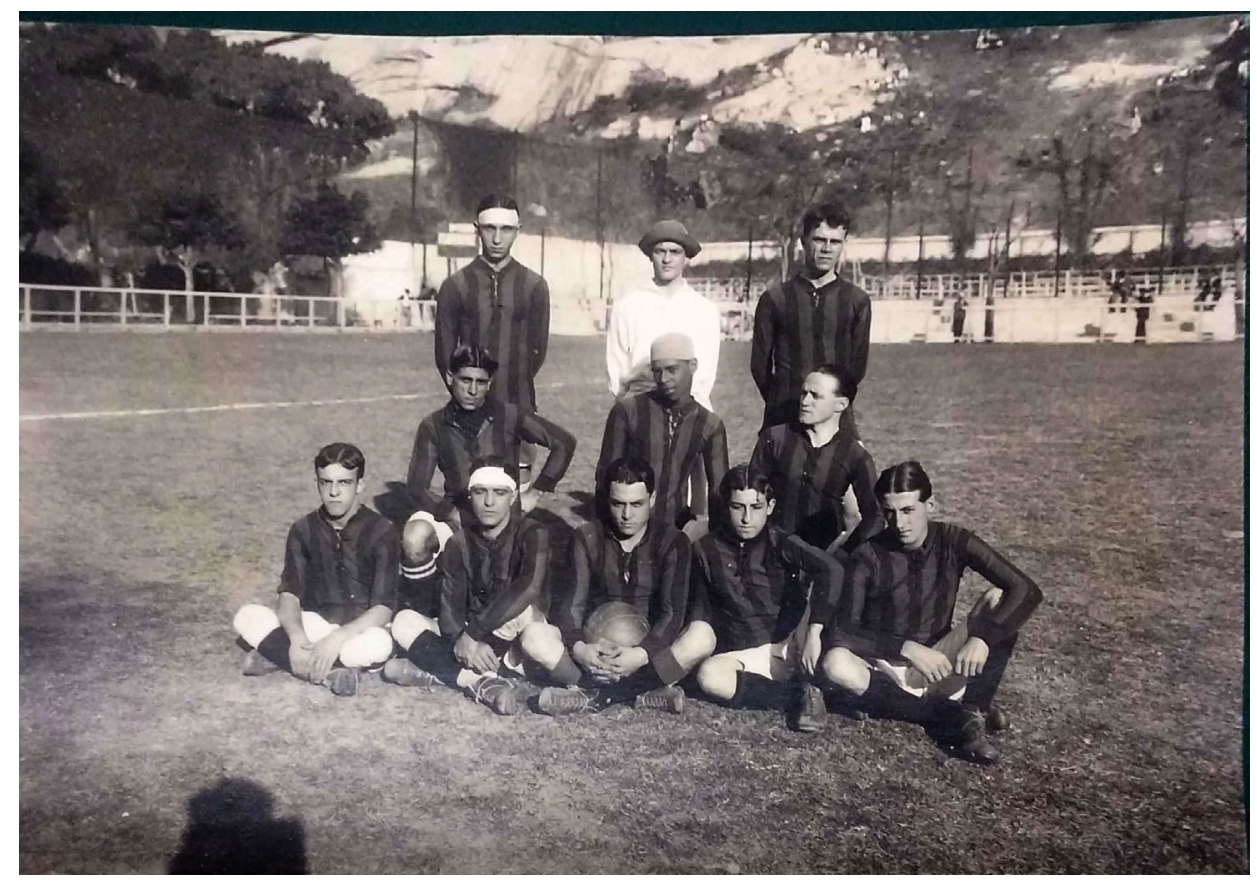

Figura 7 - Equipe Mangueira.

Fonte: Álbum Fluminense, 1917.

parece inevitável perguntar: como foi possível integrar homens negros, ou "quase negros", às fotografias do futebol amador, branco e aristocrático já no fim dos anos 1910? Quais as diferenças entre suas imagens e aquelas dos retratos canônicos da equipe do Fluminense? Por que meios suas imagens circularam? Como foram recebidas? E, principalmente, qual o seu legado para os grupos pauperizados e racializados que se organizavam em uma cidade em plena transformação?

Para responder a essas questões, é preciso iniciar considerando-se a novidade representada pelas imagens da primeira geração de negros a ser fotografada nos campos do chamado futebol oficial. E os retratados são os primeiros a oferecer as pistas para compreender essa novidade nos gestos e aparência 3 .

No retrato do clube Carioca (Figura 4) em que se entrevê maior controle sobre a configuração fotográfica, dado o ajuste das poses individuais e da equipe, há um jogador — o último, à direita, na fileira do meio - que, não se mantendo posicionado durante o tempo necessário para a captura da imagem, acaba alterando o resultado de conjunto almejado pelo fotógrafo. 
Considerando-se o mesmo aspecto, é notável ainda a diferença entre os demais retratos dos clubes novatos e os do clube Fluminense. Enquanto os jogadores do Andarahy, Carioca e Mangueira ${ }^{4}$ (Figuras 4, 5, 6 e 7) parecem experimentar os modos de posicionar braços e mãos durante a pose fotográfica, a maior parte dos jogadores do clube das Laranjeiras reificava padrões ao cruzar os braços atrás das costas ou sobre o peito (Figuras 1, 2 e 3). 0 hábito de se posicionar perante as câmeras, em ambientes privados ou em estúdios, contribuía para que os jovens do Fluminense conhecessem e realizassem poses individuais e coletivas mais padronizadas e, dessa forma, contribuíssem para fotografias mais estáveis.

Outro aspecto a ser observado nos retratos das equipes novatas relaciona-se à composição da aparência dos jogadores. Seus uniformes, chuteiras e acessórios, mais simples e menos personalizados, contrastavam com aqueles que compunham a aparência do sportsman, revelada pelo conjunto anterior de imagens (Figuras 1, 2 e 3).

Ainda sob a perspectiva da aparência, podem-se mencionar as expressões faciais dos jogadores, evidentemente mais contraídas que as dos jogadores do Fluminense, como Marcos. Aliás, o goleiro não apresentava somente um semblante descontraído na maior parte de seus retratos, mas chegava a esboçar sorrisos em vários deles, demonstrando estar atento à tendência fotográfica de incorporar essa expressão ao retrato ${ }^{5}$. Como já assinalado, Marcos procurava dar-se a ver em conformidade aos padrões utilizados para ser visto e reconhecido como parte relevante da cidade. Com esse movimento, o jogador parecia compreender a centralidade das aparências para a vida urbana.

0 mesmo pode ser dito dos jogadores negros contemporâneos de Marcos e representantes dos clubes suburbanos Andarahy Athletico Club, Carioca Futebol Clube e Sport Club Mangueira. Embora tivessem outra cor e pertencessem a outro estrato social, tais personagens reconheciam a importância da visibilidade criada pela fotografia tanto quanto os jogadores de elite. Assim, a presença de fotografias de jogadores, clubes, campos e estádios populares nos elitizados álbuns de recortes (scrapbooks) do Fluminense Football Club e de Marcos Carneiro de Mendonça naquele ano de 1917 sinalizava não apenas sua integração à liga dos autoproclamados "tradicionais" clubes da cidade, mas, sobretudo, que a visualidade hegemônica da cidade sofria uma alteração.

Por essa razão, os suportes das imagens que mencionam os três clubes no álbum do Fluminense Football Club (Figuras 4, 5, 6 e 7) merecem atenção. Como é possível notar, o Fluminense valeu-se de ampliações fotográficas para reportar a participação desses clubes novatos no campeonato de 1917 e não de recortes provenientes de jornais ou revistas ilustradas - o que era mais comum em se tratando do modelo de diário visual materializado no álbuns de recortes. 
Ainda que não tenha sido possível confirmar quando as ampliações foram integradas ao álbum, nem como foram obtidas, sua mera presença sugere que os circuitos hegemônicos de produção e de circulação de imagens administrados pela imprensa não eram os únicos a possibilitar os intercâmbios materiais e simbólicos por elas permitidos ${ }^{6}$.

É sabido que os usos da fotografia se multiplicavam à medida que os progressos técnicos a ela associados permitiam o aumento de sua produção, de sua reprodução e de sua circulação em variados campos de atuação. Assim, quando as ampliações fotográficas se tornaram o produto fotográfico com menor custo e maior potencial de reprodutibilidade disponível no mercado de imagens, os fotógrafos passaram a oferecê-las aos segmentos médios e até mesmo aos segmentos populares interessados em negociar o acesso à visualidade urbana por meio de uma identidade visual.

Assim, tornava-se cada vez mais comum contratar fotógrafos para cobrir eventos públicos, sociais e mesmo privados. Receber ofertas de quem, trabalhando de forma independente, colocava-se em locais estratégicos em tais eventos para produzir as "lembranças", ou seja, os retratos produzidos naqueles momentos, era algo corriqueiro. Após criar tais "lembranças", os fotógrafos procuravam vendê-las aos retratados, ritual nem sempre bem compreendido, como revela a anedota "Fotógrafo prático", publicada pela revista ilustrada Careta, em 1918:

em um dos pontos de passeio, preferidos pelos ranchos de moças e rapazes, nos domingos, para seus pique-niques, há um fotógrafo que ganha laboriosamente sua vida tirando retratinhos instantâneos, que entrega aos originaes em dez minutos. No último domingo houve um pique-nique muito animado. Vendo o kiosque do fotógrafo, um grupo de senhoritas lembrou-se logo de tirar uma fotografia, como lembrança da festa. Ellas formaram-se e tomaram posições poéticas, mas o fotógrafo parecia perturbado e demorava-se nos preparativos. Elle conhecia, de sciencia própria, e por penosa experiencia, que o pagamento do retrato de um grupo de moças é a cousa mais difícil de realizar. Quando há um homem no meio, é chamado a responsabilidade do caso e, ordinariamente a assume, e paga a despeza. Mas entre o grupo não havia homem. O fotografo, depois de hesitar, preparou a máquina, focalizou, e disse ao grupo: - Atenção! Firme! Fixem os olhos na taboleta! A taboleta dizia o seguinte: "Não se tiram retratos sem pagamento adiantado". A vontade de fotografar-se desapareceu do grupo, que se dissipou num instante ${ }^{7}$.

Além de cômico, o texto é rico em referências à dinâmica sociocultural animada pela fotografia. Menciona, por exemplo, a instabilidade financeira ligada ao ofício de fotógrafo ao descrever o desconforto vivido pelo profissional em face de personagens que desconheciam ou buscavam negar - o protocolo comercial vinculado à produção dos retratos. Protocolo este estabelecido, como faz questão de enfatizar o texto, por agentes do gênero masculino. 
0 conflito é interessante porque revela que o desejo e o impacto de se dar a ver pela imagem fotográfica já eram suficientemente conhecidos para que as moças soubessem se colocar em "posições poéticas". Contudo, tais saberes não pareciam estar diretamente relacionados àqueles sobre o valor de troca (o preço) dos retratos. É provavelmente por essa razão que o fotógrafo solicitava o adiantamento do pagamento ao apontar para a "taboleta". A mera existência do aviso indica a frequência com que aquela situação ocorria, além, é claro, de sugerir como o fotógrafo se protegia da inadimplência de indivíduos possivelmente insatisfeitos com as imagens.

A cena condensa, portanto, aspectos das negociações sobre o valor de uso e de troca das fotografias realizadas por grupos que começavam a experimentar os mecanismos utilizados para integrar a visualidade urbana. Como tentamos mostrar, não apenas as mulheres, mas outros grupos - especialmente boa parte da população negra — procuravam adentrar o novo e heterogêneo mercado da visibilidade social por meio da fotografia.

No contexto específico do futebol, é o repórter fotográfico José Luis da Conceição que oferece pistas sobre o funcionamento desse mercado ao narrar algumas das práticas dos fotógrafos independentes no universo do esporte amador. Ele conta que:

geralmente os fotógrafos iam [aos campos] aos domingos, sabendo que determinado time iria jogar em determinado local. lam lá para fazer a foto do time posado ou algumas individuais. E depois, durante a semana, ele já sabia, através da Liga de Futebol Amador, onde aquele time, de quem tirou a foto na semana anterior, iria jogar no próximo domingo. Então, durante a semana, ele fazia cópias, ampliava as cópias. No domingo seguinte, ele aparecia (ou outra pessoa) para vender aquelas fotos para os jogadores que ele tinha fotografado ${ }^{8}$.

0 relato permite compreender como foi sendo tecida a dimensão visual do futebol no Rio de Janeiro. Se os fotógrafos não atendiam apenas às demandas de jornais e de revistas, mas também respondiam aos desejos dos jogadores de se ver representados nas fotografias, torna-se simples imaginar que jogadores — e até mesmo alguns de seus primeiros "fãs" tenham sido clientes de fotógrafos que trabalhavam de maneira independente, paralela ou complementar à imprensa. E que suas demandas foram responsáveis por movimentar um mercado em franco desenvolvimento.

Para manter esse mercado, os fotógrafos tinham de criar soluções para otimizar 0 tempo e os recursos para produzir e fazer circular suas fotografias. Para equilibrar os custos da produção, o consumo material e a recepção simbólica das imagens, os fotógrafos procuravam satisfazer seus variados clientes construindo configurações visuais padronizadas e capazes de agradar a todos. Os desdobramentos desse recurso podem ser entrevistos em casos de sucesso $^{9}$, como o de Marcos Carneiro de Mendonça. Por corresponderem aos propósitos da 
cidade renovada, do Fluminense e do próprio goleiro, seus retratos tornaram-se uma das bases da visualidade esportiva hegemônica. Delineada em torno da figura do sportsman, essa visualidade foi reificada a cada nova fotografia até o surgimento de novos personagens na cena esportiva.

Foi, portanto, em meio à dinâmica movimentada pelas demandas e influências de novos agentes, como os esportistas negros, que a figura do sportsman começou a perder vigor. Tal fenômeno era bastante semelhante ao que acontecia nas ligas do futebol ofical à época. Além de incorporar novos clubes - o que exigia, por exemplo, alterações em seus estatutos —, as ligas passaram a se organizar sob a lógica do amadorismo marrom, isto é, do pagamento dissimulado, para atender às necessidades de seus novos jogadores.

0 momento era, pois, marcado por novos arranjos socioculturais e econômicos dos quais a busca por visibilidade e seu principal desdobramento, o reconhecimento social, tornavam-se parte fundamental. Nesse contexto, os segmentos sociais médios e mesmo alguns grupos dos segmentos populares passaram a negociar sua parcela de visibilidade com base nas expectativas criadas pelas promessas da modernidade, como explica Jean Baudrillard:

a modernidade está relacionada à capacidade que grupos e classes sociais recém-chegados ao poder têm de superar o exclusivismo dos signos, promovendo uma proliferação de signos sob demanda. 0 problema da mimese não é de estética, mas de poder social fundado na capacidade de produzir equivalências. (Baudrillard apud Crary, 1990: 21).

É, pois, em meio à "proliferação de signos sob demanda" que os fotógrafos viram suas oportunidades profissionais multiplicadas, já que eles eram os principais responsáveis por negociar e estabilizar os signos que permitiriam a integração de novos personagens à visualidade urbana.

No entanto, não se pode esquecer que os fotógrafos do Rio de Janeiro não contavam com as mesmas possibilidades de produzir "equivalências" disponíveis a Jules Beau, Félix Nadar ou Disdéri, na França. Isso porque a capacidade de modernização de uma sociedade é proporcional à sua abertura para as transformações culturais, políticas e sociais a elas associadas. No Rio de Janeiro os signos não proliferaram como aconteceu na França - em que até os populares se fizeram retratar em carros e bicicletas, tornados signos de mobilidade social.

Ainda assim, não foi possível impedir o surgimento de demandas. É considerando 0 aspecto da demanda que nos propomos a compreender como foi tecida a visibilidade de pessoas de pele negra e de populares no Rio de Janeiro por meio do futebol. Recorrendo novamente ao universo dos fotógrafos independentes, procuramos iluminar aspectos ainda pouco 
explorados da fotografia esportiva, tais como as questões da visualidade e da visibilidade popular. Sobre elas, Conceição afirma que:

os homens que jogaram futebol na várzea e que hoje tenham acima de 70 anos muito raramente terão fotos de seus familiares, de momentos da escola de seus filhos, de momentos em festas infantis etc., mas provavelmente a maior parte deles terá muitas ou algumas fotos dos times de futebol de várzea pelos quais jogaram. (Conceição, entrevsita, 2019) ${ }^{10}$.

0 repórter fotográfico afirma que as fotografias de futebol penetraram o cotidiano popular antes mesmo das de família, tornando-se também uma porta de acesso ao universo geral da fotografia. Para compreender a importância das fotografias esportivas entre as pessoas dos segmentos populares, vale lembrar que as fotografias de gênero familiar foram as primeiras a permear as práticas visuais das classes altas e médias da cidade, forjando um terreno seguro, baseado em laços familiares, para seus processos de subjetivação.

Em contraste, uma visualidade e a visibilidade popular e masculina foi sendo constituída em meio às trocas simbólicas efetuadas pela fotografia no específico âmbito do lazer, ou seja, do tempo e do espaço livres. Mas, para compreender o grau de inovação representado pela integração de pobres e negros a esse campo visual, é necessário retornar ao fim do século XIX para recuperar os modos como esses grupos foram antes retratados.

\section{NEGOCIAÇÕES EM TORNO DA VISIBILIDADE SOCIAL: ANTECEDENTES VISUAIS}

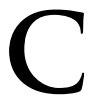

omo vimos, a renovação do Rio de Janeiro pelas reformas urbanas conduzidas por

Pereira Passos resultou em uma nova organização da cidade e em uma nova partilha do sensível. Esta

faz ver quem pode tomar parte no comum em função daquilo que faz, do tempo e do espaço em que essa atividade se exerce. Assim, ter esta ou aquela "ocupação" define competências ou incompetências para o comum. Define o fato de ser ou não visível num espaço comum. (Rancière: 2000: 16).

Com o auxílio das lentes de fotógrafos, uma pequena parcela da sociedade do Rio de Janeiro fazia-se visível, obtendo legitimidade para caminhar no espaço valorizado da cidade, enquanto mais da metade da população da cidade se tornava invisível. Em face do discurso de que eram desajustados aos novos tempos e espaços da cidade, os grupos populares iam sendo expulsos também do tempo-espaço fotográfico e, diante da impossibilidade de reconhecer os referenciais visuais associados à sua experiência nas regiões centrais da cidade, essa população tornava-se invisível até mesmo para si própria. 
A estratégia estatal, empregada em outras cidades do ocidente, consistia em invisibilizar pessoas cujos modos de ser e de viver a cidade não estivessem previstos em suas novas configurações. Não se pode esquecer que, até o momento das reformas, a cidade "parecia pertencer aos escravos" (Chalhoub, 1996: 31), como costumavam afirmar administradores, legisladores públicos e empresários do ramo imobiliário, que frequentemente eram as mesmas pessoas. Muito embora se soubesse que a cidade não "pertencia" aos escravos, sua presença, seus hábitos e sua circulação eram marcantes o suficiente para preocupar àqueles que planejavam atribuir novas marcas à cidade.

Para modificar os usos que os habitantes faziam da cidade e reduzir possíveis "ameaças" ao controle estatal e econômico atualizado com as reformas urbanas, tais poderes organizaram-se para atuar visual e fotograficamente. Isso não representava novidade para tais grupos.

Ora, não se pode esquecer de que os anos iniciais da fotografia no país coincidiram, irônica e paradoxalmente, com os anos finais da escravidão. Promovido pela monarquia e por grandes fazendeiros, o encontro entre o símbolo máximo da modernidade, a fotografia, e seu correspondente em termos de atraso internacional, a escravidão, criou um inédito, amplo e perverso panorama visual sobre a população negra e o sistema escravista. Isso é ilustrado nas Figuras 8,9 e 10 .

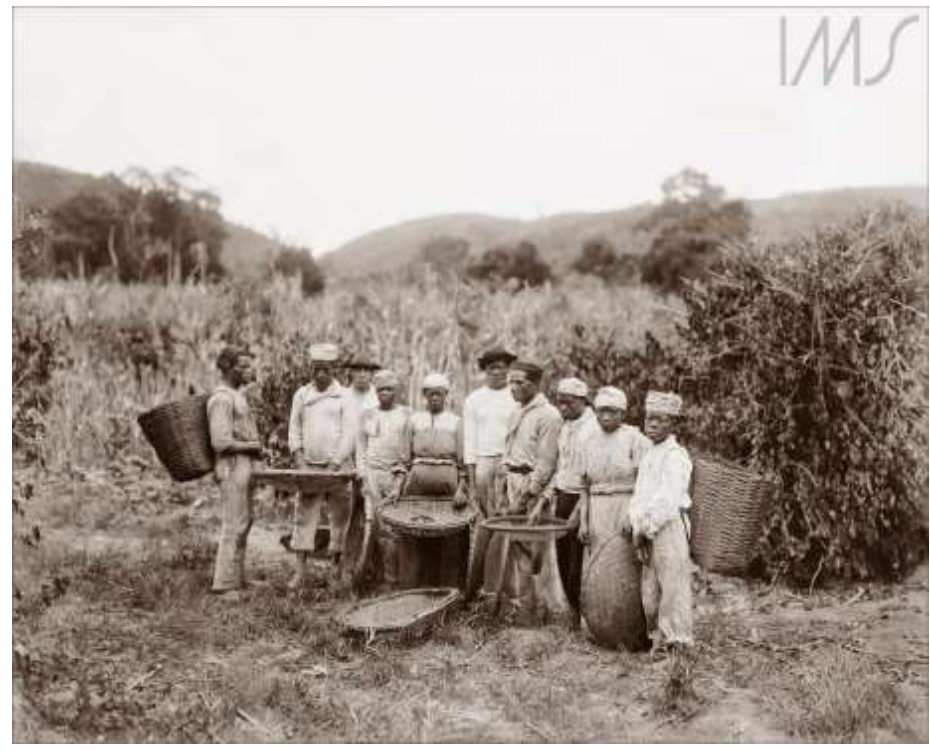

Figura 8 - Escravos na colheita do café. Ferrez, Marc (c. 1882).

Fonte: Brasiliana Fotográfica. Disponível em: <http://brasilianafotografica.bn.br/brasiliana/handle/20.500.12156.1/2137>. Acesso em: 18 nov. 2020. 


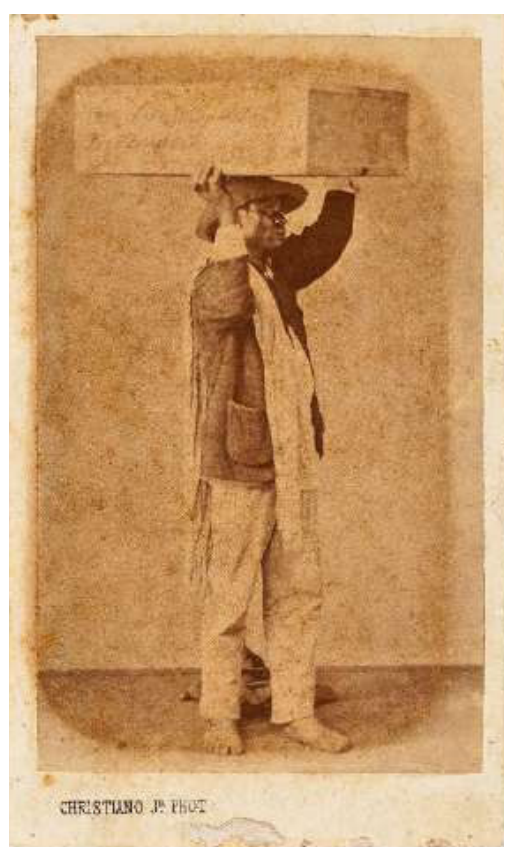

Figura 9 - Escravo de ganho com caixa em cima da cabeça, 1864-1865. Fonte: Christiano Junior. Rio de Janeiro, RJ/Acervo Museu Histórico Nacional.

Disponível em: <http://brasilianafotografica.bn.br/brasiliana/handle/20.500.12156.1/6497>. Acesso em: 18 nov. 2020.

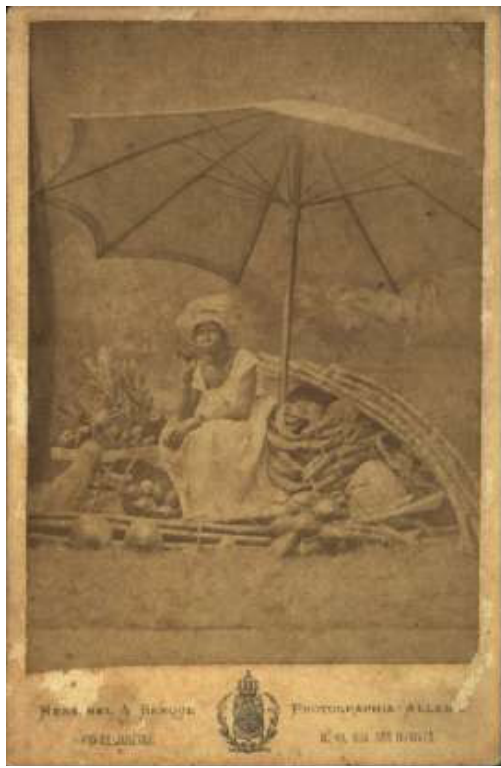

Figura 10 - Mulher de pele negra vendedora de frutas.

Fonte: Alberto Henschel., 187- / Acervo Fundação Biblioteca Nacional.

Disponível em: <http://brasilianafotografica.bn.br/brasiliana/handle/20.500.12156.1/9>. Acesso em: 18 nov. 2020. 
As séries sobre o trabalho nas fazendas de café de autoria de Marc Ferrez, os retratos de Christiano Jr. e de outros fotógrafos no formato carte de visite dedicados a reportar os ofícios e as ocupações de homens e mulheres escravizados, livres e libertos são alguns dos gêneros de fotografias mais encontrados no repertório visual sobre a população negra criado a partir da segunda metade do século XIX ${ }^{11}$.

Embora à época fossem categorizadas como retratos, as três imagens acima mencionadas $^{12}$ não estavam comprometidas com a promoção da singularidade de sujeitos considerados individual ou coletivamente, tal como ensinavam os manuais de fotografias voltados a esse gênero fotográfico ${ }^{13}$. Essa impressão confirma-se no anúncio de venda dos cartes de visite de Cristiano Jr. publicados no almanaque Laemmert, em 1866: "variada coleção de costumes e typos de pretos, cousa muito própria para quem se retira para a Europa" (apud Mauad 2000: 89-90). Ora, as imagens eram anunciadas como parte de uma coleção de exemplos, de tipos.

Ao observar tais imagens, sobretudo aquelas dos suportes cartes de visite (Figuras 9 e 10), é possível notar que os objetos nelas mencionados são tão ou mais importantes que as próprias pessoas retratadas, figurando como os signos de certas tarefas ou ofícios. Havia uma espécie de codificação desses objetos, das paisagens e dos cenários em que as atividades se desenrolavam. Havia também uma menção ao gênero e à faixa etária dos personagens que executavam as tarefas. As imagens estavam dedicadas a caracterizar o trabalho e não a pessoa fotografada.

As pesquisas dedicadas a essas imagens revelam que a mobilização de signos como os mencionados tornou possível a criação de coleções de "typos de pretos", que permitiam aos observadores "mapear" as ocupações, os ofícios, os gêneros e os locais de trabalho de pessoas negras escravizadas, libertas ou livres. Tratava-se, em verdade, de um gênero fotográfico destinado a uma tipificação e ao controle visual sobre a população negra — e não de retratá-la segundo os cânones do retrato ${ }^{14}$.

De outro lado, como também sugerido pelo anúncio de Christiano Jr., a circulação dessas imagens não se restringiu ao território nacional, de modo que os conteúdos relacionados ao controle não foram os únicos a circular por meio delas. Segundo Mariana Muaze, fotógrafos como

\footnotetext{
Alberto Henschel, Rodolpho Lindemann, Felipe Augusto Findanza, João Goston, João Ferreira Villela, Auguste Stahl, Christiano Jr. e Marc Ferrez produziram imagens de "tipos pretos" e exóticos que atendiam fortemente ao mercado consumidor estrangeiro e tinham grande circulação e consumo garantidos. Nesses casos, interessava a representação dos negros como escravos e dos costumes vividos em terras distantes. Tratava-se de [oferecer] um "retrato do negro para o branco". (Muaze, 2017: 37).
} 
Ou seja, as imagens construídas sobre a população negra escravizada também atendiam a demandas do mercado europeu de fotografias, sobretudo o francês, como deixa entrever a trajetória de Marc Ferrez. Muaze revela que Ferrez, um brasileiro descendente de franceses, dedicou-se a produzir fotografias para o mercado internacional, sobretudo aquele das exposições universais. Ofereceu, assim, um universo fotográfico em estreita sintonia com

o mundo dos grandes proprietários escravistas, que viviam entre a nostalgia de um passado em que a escravidão era um sistema incontestável do ponto de vista econômico e humanitário, e a perspectiva da construção de uma sociedade moderna a exemplo das nações europeias. (Muaze, 2017: 35).

Ferrez produziu fotografias de escravizados que atendiam a demandas imperiais dentro e fora do país, alimentando um jogo de espelhos que parecia reger a recepção dessas imagens nos dois lugares. Isso, sobretudo, porque um de seus conhecidos efeitos foi a formação de um imaginário estável (embora fictício) sobre o pacífico e ordenado trabalho compulsório no Brasil.

Por essa razão, experiências fotográficas não hegemônicas, que contrariavam os padrões visuais financiados pelos barões do café, não lograram maior alcance nem aqui, nem na Europa. Esse é o caso dos circuitos que envolviam os retratos de homens e mulheres libertos ou livres. Buscando tomar parte nos sentidos promovidos pelas fotografias, muitos deles experimentaram produzir aparências com base no que era oferecido nos estúdios àqueles que por elas podiam pagar. Suas imagens — prova incontestável de que mudanças no circuito do retrato estavam associadas a alterações sociais mais profundas — frustravam as expectativas de uma recepção mais interessada em reificar a "partilha do sensível", segundo os lugares sociais estabelecidos pela lógica imperial.

Aliás, é em meio à lógica imperial que atributos como a cor da pele dos fotografados haviam funcionado como signos para fixar os seus lugares sociais nas imagens, como faziam as vestimentas ou o mobiliário nos retratos das famílias da corte. Por essa razão, figurar como um sujeito nos retratos da época tornava-se tarefa tão complexa para as pessoas de pele negra quanto as negociações sobre a sua liberdade. Vale dizer que, embora complexa, a tarefa não foi impossível para muitas delas ${ }^{15}$.

De todo modo, o conjunto fotográfico hegemonicamente produzido e consumido nos anos finais da escravidão no Brasil indica, ainda segundo Muaze, o empenho em "eternizar um mundo escravista" por meio do "discurso visual de uma 'escravidão apaziguada'" (Muaze, 2017: 57-58). Tendo, pois, por base as fotografias de uma população ocupada e 
identificada com seus ofícios, promovia-se uma imagem de trabalho autorreferente, sem que "proprietários" ou patrões precisassem ser diretamente nela mencionados.

Ora, em face dos desejos de modernização sem ruptura no Brasil e da organização dos trabalhadores na Europa em prol de uma série de reivindicações, torna-se simples imaginar 0 interesse mútuo por imagens de trabalho sem conflito naquele fim de século. Cafeicultores e representantes do Império, bem como os consumidores de imagens das exposições universais, em geral europeus "donos dos meios de produção", compartilharam com os fotógrafos a tarefa de promover um apaziguamento nas relações envolvendo o mundo do trabalho.

É, pois, diante desse panorama que se pode afirmar que a tipificação de pessoas com base no trabalho compulsório figura como o principal conteúdo visual das fotografias realizadas sobre a população negra no fim do século XIX - e que a invisibilização de seus descendentes caracteriza as fotografias feitas anos depois, já sob as reformas de Passos. 0 controle da população negra baseado em imagens de trabalho e de convivência pacífica cedeu lugar a outro, no qual esses mesmos trabalhadores, ou seja, vendedores de frutas, engraxates, carregadores etc., eram sistematicamente excluídos do espaço fotográfico urbano como estratégia para prefigurar novos usos da cidade.

Essas foram as principais experiências visuais por intermédio das quais se negociou a presença de populares e de pessoas de pele negra nas fotografias de futebol. Associadas àquelas que deram origem à figura do sportsman, elas conformam o pano de fundo com 0 qual inevitavelmente dialogamos ao observar os retratos dos jogadores do Andarahy, Carioca e Mangueira que são mencionadas no início deste artigo (Figuras 4, 5, 6 e 7). Com base nesse panorama, podemos concluir retomando o contexto de transição do futebol amador ao profissional.

\section{CONSIDERAÇÕES FINAIS}

$\mathrm{O}$ s retratos das equipes suburbanas presentes no álbum do Fluminense de 1917 revelaram a emergência de novos atores no cenário esportivo da cidade. Revelaram também uma heterogeneidade cultural ainda não controlada ou codificada pela fotografia, bem como a série de agentes interessados nessa codificação via mercado fotográfico.

A nosso ver, contudo, a dimensão mais importante à qual as imagens aludem é a mudança no padrão de visibilidade social oferecido à população negra. Isso, primeiramente, porque retratar é o oposto de invisibilizar. Ainda que os retratos de equipe não dialogassem com a singularidade de cada um dos sujeitos - o que só viria a acontecer anos depois, com Leônidas da Silva — atribuíam-Ihes uma identidade visual de conjunto, baseada no pertencimento à equipe esportiva. 
Em segundo lugar, os retratos estavam associados ao universo do esporte, do entretenimento e do lazer e não ao do trabalho. Tratava-se de uma grande transformação simbólica. Apenas trinta anos após o fim da escravidão, passava-se do "tipo" escravizado ao retrato de jogador de futebol amador. Isso qualificava positivamente homens de pele negra, uma vez que suas imagens estavam associadas ao tempo livre e não ao tempo do trabalho compulsório. Sob esse aspecto, pouco importava se o amadorismo da maior parte deles dissimulava honorários esportivos.

Tratava-se de uma modalidade de amadorismo estabelecida para reafirmar o valor simbólico do tempo livre como um atributo de origem, uma medida da elite para conter os signos, valores e práticas associados ao futebol profissional, ou seja, ao futebol tratado como mercadoria. Nesse sentido, não deixa de ser irônico o fato de que homens negros tenham representado tanto o futebol amador quanto o futebol profissional, pouco tempo depois.

Por essas razões, as transformações socioculturais dos anos finais da década de 1910 foram mais significativas do que se costuma reconhecer, pois representaram um momento de importante protagonismo da população negra nas negociações sobre a visibilidade social e o pertencimento ao espaço urbano renovado. Esse movimento contribuiu para dinamizar e fortalecer o mercado fotográfico que começava a se reconfigurar. Ao mesmo tempo, permitiu que homens negros se aproximassem das promessas associadas à modernidade, ao menos daquelas relacionadas à construção e à mobilização de signos de pertencimento a certos grupos e espaços sociais. Anos depois, em meio à propagação de tais signos no contexto de formação dos conglomerados midiáticos, eles seriam corresponsáveis pelo surgimento da figura do craque de futebol.

Conflitos de interesse: nada a declarar.

Fonte de financiamento: nenhuma.

\section{NOTAS}

1 Primeiro goleiro da seleção brasileira, Marcos Carneiro de Mendonça foi, entre 1914 e 1918, o principal goleiro do Fluminense Football Club. Oriundo de família rica e agrária, destacou-se fora de campo como historiador e colecionador. Entre seus feitos, está a produção de um álbum fotográfico de memórias, hoje na Biblioteca Nacional. 
2 Para uma análise da construção social de Marcos Carneiro de Mendonça, cf. Silva (2006).

3 Aqui compreendida no sentido oferecido por Hannah Arendt, como "aquilo que é visto e ouvido pelos outros e por nós mesmos" e que, afinal, "constitui a realidade" (Arendt, 2016: 61). Trata-se, pois, de uma reciprocidade. Partilhamos o real por meio da aparência que, por sua vez, é definida como aquilo que é percebido e partilhado. A noção de aparência tem sido central ainda para a análise do contexto de transformação das cidades, da vida social e do sujeito na modernidade, sob a perspectiva da percepção e da estética social. A respeito do tema, ver, por exemplo, Carnevali (2013), além de Coccia (2010).

40 Andarahy foi fundado em 1909 por funcionários da fábrica de tecidos Cruzeiro. 0 Carioca Futebol Clube da zona sul do Rio de Janeiro foi fundado no mesmo ano. Já o Sport Club Mangueira foi fundado anos antes, em 1906, na Tijuca.

5 Ao contar brevemente a história do sorriso no retrato, André Gunthert (2017) afirma que é no início do século XX que se começa a experimentá-lo com maior frequência, até ele se tornar um signo fotográfico importante nos anos 1930.

6 Assim, mesmo que o Fluminense não disponha das informações que permitiriam mapear as práticas de aquisição e de salvaguarda de suas fotografias nos primeiros anos de atuação do clube, foi possível inferir algumas por esses circuitos não "hegemônicos" das imagens. Quanto ao acervo do clube, Heitor D'Allincourt, historiador do Fluminense, contou-nos por telefone que os anos iniciais do clube carecem de documentação sobre esse tema. Antigos associados reportavam-Ihe lembranças da presença frequente de um fotógrafo amador, também padre, em todos os eventos do clube. Como tinha especial predileção pelo futebol, o religioso teria sido uma das primeiras pessoas a produzir imagens sobre o esporte na associação. A narrativa é interessante sobretudo porque revela o esforço do clube em manter todas as suas atividades associadas ao amadorismo naquele período. Informações mais consistentes sobre a constituição do acervo visual do clube remetem a momentos posteriores, em que fotografias e outros objetos começam a ser doados por antigos jogadores, associados, repórteres fotográficos e mesmo periódicos, forjando a base memorial da instituição.

7 Careta, edição 0528, 3 ago. 1918.

8 Antigo repórter fotográfico de periódicos de grande circulação em São Paulo. Entrevista realizada em 23 de fevereiro de 2019.

9 Considerando-se, evidentemente, as possibilidades e as realizações da época, pois não eram raras imagens que revelassem as tentativas e erros de fotógrafos quanto à escolha do local, do ângulo e do foco da fotografia, tais como revelam as imagens aqui analisadas, seja pela projeção de sombras, pelo corte do cenário e até mesmo pela "aparição" de personagens 
não previstos na cena. Nesse sentido, chamamos de bem-sucedidas as configurações visuais capazes de reunir os signos visuais relacionados às demandas dos principais agentes do campo esportivo e fotográfico em formação: cidade, clube, equipe, jogadores, fotógrafos, jornais, revistas ilustradas, entre outros.

10 Entrevista de José Luis da Conceição concedida à autora em 23 de fevereiro de 2019.

11 Além desses conjuntos, é preciso mencionar aquele formado pelas gravuras e retratos falados, que reportavam as fisionomias de escravizados fugidos ou desaparecidos. Tais imagens acabaram figurando como modelos para a produção de fotografias criminais já no fim do século XIX.

12 Que integram coleções mais amplas, ver: <http://brasilianafotografica.bn.br/?tag=escravidao>. Para uma análise desse material, ver Mauad (2000), Muaze (2017), bem como Schwarcz e Machado (2018).

13 Os manuais de fotografias que circularam no Rio de Janeiro e em São Paulo tinham como função auxiliar os fotógrafos a realizar bons retratos das "boas" famílias aristocráticas que os procuravam. Para tanto, oferecia-se uma série de dicas que abrangia desde a compra e 0 manuseio dos equipamentos, passando pela composição de poses e cenários, até as formas de tratar os fotografados no estúdio (cf. Grangeiro, 1998).

14 Ver Natália Brizuela, Fotografia e império, São Paulo, Companhia das Letras, 2012.

15 Cf. Beltramin, 2013.

\section{REFERÊNCIAS BIBLIOGRÁFICAS}

ARENDT, H. A condição humana. 13. ed. Rio de Janeiro: Forense Universitária, 2016.

BELTRAMIN, F. Sujeitos iluminados: a reconstituição das experiências vividas no estúdio de Christiano Jr. São Paulo: Alameda, 2013.

BERGER, J. Para entender uma fotografia. São Paulo: Companhia das Letras, 2017.

CARNEVALI, B. L'esthétique sociale entre philosophie et sciences sociales. Tracés - Revue de Sciences Humaines, Lyons, n. 3, p. 29-48, 2013. Disponível em: <https://journals.openedition.org/traces/5685>. Acesso em: 18 nov. 2020. https://doi.org/10.4000/traces.5685.

CHALHOUB, S. Cidade febril. São Paulo: Companhia das Letras, 1996.

COCCIA, E. La vie sensible. Paris: Rivages, 2010.

CRARY, J. Técnicas do observador: visão e modernidade no século XIX. São Paulo: Contraponto, 1990.

GRANGEIRO, C. D. As artes de um negócio: no mundo da técnica fotográfica do século XIX. Revista Brasileira de Historia, São Paulo, v. 18, n. 35, p. 185-205, 1998. Disponível em: <https://www.scielo.br/scielo. 
php?pid=S0102-01881998000100008\&script=sci_arttext\&tlng=pt>. Acesso em: 18 nov. 2020. http://dx.doi.org/10.1590/S0102-01881998000100008.

GUNTHERT, A. Le sourire photographique, ou les révolutions du portrait expressif. L'Image Sociale, 5 abr. 2017. Disponível em: <https://imagesociale.fr/4275>. Acesso em: 9 set. 2019.

SCHWARCZ, L. M.; MACHADO, M. H. P. T. (orgs.). Emancipação, Inclusão e Exclusão: desafios do passado e do presente. São Paulo: Edusp, 2018.

MAUAD, A. M. As fronteiras da cor: imagem e representação social na sociedade escravista imperial. Locus Revista de História, v. 6, n. 2, p. 83-98, 2000. História e Leituras. Disponível em: <https://periodicos.ufjf.br/ index.php/locus/article/view/20515>. Acesso em: 9 set. 2019.

MUAZE, M. A. F. Violência apaziguada: escravidão e cultivo do café nas fotografias de Marc Ferrez (18821885). Revista Brasileira de Historia, São Paulo, v. 37, n. 74, p. 33-62, 2017. Disponível em: <http://www. scielo.br/scielo.php?script=sci_arttext\&pid=S0102-01882017000100033\&lng=en\&nrm=iso>. Acesso em: 1 set. 2020. https://doi.org/10.1590/1806-93472017v37n74-02.

PEREIRA, L. A. M. Footballmania: uma História social do futebol no Rio de Janeiro, 1902-1938. Rio de Janeiro: Nova Fronteira, 2000.

RANCIÈRE, J. A partilha do sensível. São Paulo: Editora 34, 2000.

RODRIGUES FILHO, M. O negro no futebol brasileiro. Rio de Janeiro: Mauad, 1994.

SILVA, M. R. Mil e uma noites de futebol. O Brasil moderno de Mario Filho. Belo Horizonte: Editora UFMG, 2006. 